\section{The 'smoking gun' in ALS}

\section{By Lev Osherovich, Senior Writer}

A spate of reports buttresses the case for TDP- 43 as a key player in amyotrophic lateral sclerosis. But even though the protein is mislocalized in a majority of patients, drug developers are holding off on targeting TDP-43 until more is known about its function. Instead, most companies are sticking with better-studied targets such as neuronal receptors and another mutated protein, superoxide dismutase 1.

Amyotrophic lateral sclerosis (ALS) is a debilitating neurodegenerative disorder that causes loss of sensation, motor difficulties and paralysis. ALS is usually sporadic, but a small number of cases have previously been linked to hereditary mutations in superoxide dismutase 1 (SOD1).

SOD1's normal function is to lower superoxide radicals inside of cells, but SOD1-linked ALS does not merely result from loss of normal SOD1 activity. In familial ALS patients, SOD1 forms toxic intracellular aggregates, although the mechanism by which this leads to clinical disease is poorly understood.

Only one drug, Rilutek riluzone from sanofi-aventis Group, is approved for ALS. It extends survival and time to tracheostomy by reducing glutamate neurotransmitter levels, but lifespan is extended only a few months. ${ }^{1}$

Rilutek, as well as neurotrophic factor therapeutics in various stages of development, boost neuronal health but are not thought to directly affect protein aggregation (see Table 1, "Amyotrophic lateral sclerosis pipeline").

Now, a study published in Science by an international team led by Christopher Shaw of King's College London describes hereditary and sporadic mutations in human TDP-43 that also cause ALS. ${ }^{2}$ The gene-mapping study involved five individuals from the same family. The researchers validated their results by finding TDP-43 mutations in 3 unrelated sporadic ALS patients out of a 526-patient cohort. Like SOD1, TDP-43 forms aggregates in the neurons of ALS patients.

In a concurrent Journal of Biological Chemistry paper, a group led by Virginia Lee, professor of pathology and lab medicine at the University of Pennsylvania School of Medicine, reported a new cell culture model for TDP-43 pathology. ${ }^{3}$ The team found that engineered versions of TDP-43 missing the nuclear localization sequence mislocalize to the cytoplasm and form ubiquitinated aggregates, a hallmark of ALS pathology.

Shaw said his group's findings lay to rest the question of whether TDP-43 is a culprit or bystander in the disease.
The publication is "the smoking gun that validates the pathology" of TDP-43 in ALS, according to Lee, whose group first reported the presence of abnormally localized TDP-43 in the brains of ALS patients in 2006. ${ }^{4}$

"TDP-43 had already been identified in ALS, but it was thought that it was a piece of cellular junk, not the cause of disease," Shaw told SciBX. His team identified three separate mutations that were sufficient to cause ALS, and they went on to show in a chick embryo model of neural development that mutant forms of the protein can cause pathology. Shaw said the study is "the first mechanistic link" between TDP-43 and ALS.

It thus appears that both SOD1 and TDP- 43 form toxic protein aggregates in the cytoplasm, although it's still unknown whether these problems are related or how they ultimately lead to motor neuron damage.

A hint at the downstream events in ALS comes from a new study of neuropathology caused by expressing mutant SOD1 in mice. The report in Nature Neuroscience shows the accumulation of antibodies and other serum proteins around damaged neurons, suggesting a breakdown of the barrier between the blood and the nervous system. ${ }^{5}$ The work was conducted by a University of Rochester Medical Center team lead by Berislav Zlokovic.

Jeff Rothstein, professor of neurology at Johns Hopkins University, told SciBX that researchers are divided about which of the two proteins is more important in sporadic ALS, which is considerably more common than the SOD1- or TDP-43-linked derivations of the disease. "The SOD1 side of the world thinks that SOD1 aggregation could account for sporadic ALS" in addition to the hereditary form, said Rothstein. "Now the TDP-43 camp has a stronger case."

The aforementioned reports, along with another genetic study published in the Annals of Neurology that shows an additional hereditary TDP-43 mutation is linked with ALS, ${ }^{6}$ could cause a paradigm shift in research, according to Lee.

Many therapeutics in development target SOD1 or SOD1-related biochemical pathways, which may underpin only a minority of ALS cases, said Shaw. A change of focus to TDP- 43 would be more productive, he explained, because "95\% of all people with ALS have TDP-43 aggregates, but we've been trying to treat a SOD1 model."

Industry researchers, however, want a bit more data before they change direction. Frank Bennett, SVP of research at Isis Pharmaceuticals Inc., said Shaw's paper was an important step forward, but he thinks it is "still an open question" whether TDP-43 is a good drug target. The company's ISIS 333611, an antisense inhibitor of SOD1 expression, is in preclinical development for ALS.

Bennett told SciBX that knocking down SOD1 might still be useful in treating sporadic ALS, which could potentially arise from problems with TDP-43 or other proteins that may ultimately influence SOD1 activity.

"It's nice to finally see the purely correlative observations relating TDP-43 inclusions to ALS confirmed through genetic linkage analysis," said Chris Wigley, VP of research at Reata Pharmaceuticals Inc. Wigley said Reata still will focus its ALS efforts on small molecules that 
Table 1. Amyotropic lateral sclerosis pipeline. Selected compounds in development for ALS.

\begin{tabular}{|c|c|c|c|}
\hline Company & Product & Description & Status \\
\hline Avicena Group Inc. (OTCBB:AVGO) & AL-02 & Formulation of creatine & $\begin{array}{l}\text { Start Phase III } \\
\text { in } 2 \mathrm{H} 08\end{array}$ \\
\hline $\begin{array}{l}\text { Mitsubishi Tanabe Pharma Corp. } \\
\text { (Tokyo:4508; Osaka:4508) }\end{array}$ & Edavarone (MCI-186) & Free radical scavenger & Phase III \\
\hline CytRx Corp. (NASDAQ:CYTR) & Arimoclomol & $\begin{array}{l}\text { Hydroxylamine derivative that induces heat shock protein } \\
\text { expression }\end{array}$ & Phase $\mathrm{IIb}^{\mathrm{A}}$ \\
\hline Faust Pharmaceuticals S.A. & FP0011 & Orally available small-molecule glutamate inhibitor & Phase II \\
\hline $\begin{array}{l}\text { Ono Pharmaceuticals Co. Ltd. } \\
\text { (Tokyo:4528; Osaka:4528) }\end{array}$ & $\begin{array}{l}\text { Cereact capsule } \\
\text { (ONO-2506PO) }\end{array}$ & Astrocyte modulator & Phase II \\
\hline $\begin{array}{l}\text { Teva Pharmaceutical Industries Ltd. } \\
\text { (NASDAQ:TEVA) }\end{array}$ & Talampanel & AMPA receptor blocker & Phase II \\
\hline Teva & $\begin{array}{l}\text { Copaxone glatiramer } \\
\text { acetate }\end{array}$ & $\begin{array}{l}\text { Selective major histocompatibility complex (MHC) class II } \\
\text { modulator }\end{array}$ & Phase $\mathrm{II}^{\mathrm{B}}$ \\
\hline Tikvah Therapeutics Inc. & TIK-201 & Sodium phenylbutyrate & Phase II \\
\hline Avicena & AL-08 plus celecoxib & Formulation of creatine plus celecoxib & $\begin{array}{l}\text { Start Phase II } \\
\text { in } 2008\end{array}$ \\
\hline Sangamo BioSciences Inc. (NASDAQ:SGMO) & SB-509 & Transcriptional activator of VEGF-A & $\begin{array}{l}\text { Start Phase II } \\
\text { in } 2008\end{array}$ \\
\hline Aeolus Pharmaceuticals Inc. (OTCBB:AOLS) & $\begin{array}{l}\text { Manganese porphyrin } \\
\text { (AEOL 10150) }\end{array}$ & Catalytic antioxidant & Phase I \\
\hline Knopp Neurosciences Inc. & KNS-760704 & Optical enantiomer of dopamine agonist pramipexole & Phase I \\
\hline Phytopharm plc (LSE:PYM) & Myogane & Nonpeptide neurotrophic factor inducer & Phase I \\
\hline Trophos S.A. & TRO19622 & $\begin{array}{l}\text { Small molecule with cholesterol-like structure that interacts } \\
\text { with the mitochondrial permeability transition pore }\end{array}$ & Phase I \\
\hline Vasogen Inc. (TSX:VAS; NASDAQ:VSGN) & VP025 & Anti-inflammatory compound that modulates cytokine levels & Phase I \\
\hline Ceregene Inc. & CERE-130 & $\begin{array}{l}\text { Adeno-associated virus vectors carrying insulin-like growth } \\
\text { factor-1 }\end{array}$ & Preclinical \\
\hline $\begin{array}{l}\text { RXi Pharmaceuticals Corp. (NASDAQ:RXII), } \\
\text { subsidiary of CytRx Corp. }\end{array}$ & $\begin{array}{l}\text { Interfering RNA } \\
\text { compound }\end{array}$ & RNAi compound inhibiting superoxide dismutase (SOD1) & Preclinical \\
\hline Isis Pharmaceuticals Inc. (NASDAQ:ISIS) & ISIS 333611 & Second-generation antisense inhibitor of SOD1 & Preclinical \\
\hline $\begin{array}{l}\text { Neuren Pharmaceuticals Ltd. (ASX:NEU)/ } \\
\text { Metabolic Pharmaceuticals Ltd. (ASX:MBP) }\end{array}$ & NNZ-4945 & Neural regeneration peptide & Preclinical \\
\hline NeuroNova $\mathrm{AB}$ & sNN0029 & VEGF protein & Preclinical \\
\hline Reata Pharmaceuticals Inc. & RTA801 & SOD1 protein-folding stabilizer & Preclinical \\
\hline Sygnis Pharma AG (FSE:LIO) & AX200 & G-CSF & Preclinical \\
\hline
\end{tabular}

AIn January, the FDA placed a clinical hold on the trial and requested additional analyses of previously completed animal toxicology studies. ${ }^{B}$ In March, the company reported that the compound missed the primary endpoint in a Phase II trial.

modulate the stability and folding of mutant SOD1, but it will keep an eye out for other potential targets such as TDP-43.

Reata's RTA801, a small molecule that stabilizes SOD1 in its native conformation, is in preclinical development to treat ALS.

Wigley suggested that combining knowledge of the hereditary and sporadic TDP-43 mutations identified by Shaw's group and the new assay reported by Lee's group could be useful in working out the disease mechanism. The TDP-43 mutations in the Shaw study were in a different part of the protein from the region identified by Lee, suggesting that multiple parts of the protein could contribute to ALS.

Very little is known about the normal biology of TDP-43, thus complicating efforts to directly target it. Initially identified as a protein that interacts with HIV DNA, TDP-43 is also involved in mRNA splicing. Rothstein suggested that at least some of the pathology of ALS could be due to the inability of mislocalized TDP-43 to participate in splicing; he cited clinical similarities between ALS and spinomuscular atrophy, which is caused by defects in an RNA-binding protein called survival of motor neuron 1.

Alternatively, ALS could result from the toxic effects of TDP-43 mislocalization. Lee's group found that expressing mutant TDP-43 in neurons caused normal TDP-43 to get stuck in the cytoplasm, forming ubiquitin-rich aggregates. Cytoplasmic inclusions full of ubiquitinated TDP-43 and other proteins are a common feature of neurodegenerative diseases such as Parkinson's disease.

Lee believes that TDP-43 aggregation also could underlie frontotemporal dementia, a form of cognitive impairment that sometimes accompanies ALS.

Rothstein said questions about the mechanism of TDP-43 toxicity and what therapeutic strategy to take will be easier to address once mouse models emerge. If knocking out TDP-43 causes ALS-like dis- 
ease, or overexpression causes cytoplasmic aggregation and ALS-like pathology, the new protein could be a promising target for therapeutics.

"Once you have the mouse, you'll have a full platform," said Rothstein. For now, he said, it would be premature to "throw out the SOD model."

Even if TDP-43 proves to be primarily responsible for ALS, its ubiquitous expression and normally nuclear localization would make it a difficult drug target, according to Franz-Werner Haas, VP of operations at Sygnis Pharma AG.

Regardless of the specific disease mechanism, Haas said, Sygnis' AX200 recombinant G-CSF could have a broadly neuroprotective effect in ALS. The company plans to begin Phase I trials of AX200 in ALS this year.

Hopkins' Rothstein is a founder of Ruxton Pharmaceuticals Inc., which aims to treat ALS by increasing glutamate transporter expression, which saves wear and tear on ALS-damaged neurons by lowering glutamate levels.

Other biotechs are also staying above the SOD1 and TDP-43 fray by targeting steps in nerve growth, angiogenesis and immune response that could ward off the degenerative effects of ALS in motor neurons. Compounds that target these processes are thought to act further downstream in the disease process than either SOD1 or TDP43 and aim to reduce the severity of disease symptoms.

However, the track record for such drugs has thus far been poor, according to Aimee Kao, assistant adjunct professor of clinical neurology at the University of California, San Francisco. "By the time you see symptoms, the damage is too far gone" for nerve-preserving therapies to have much effect, she said.

Therapies aimed at a suspected autoimmune response in ALS have also been unsuccessful. For example, Teva Pharmaceutical Industries Ltd. announced this month that a Phase II trial of Copaxone glatiramer acetate for ALS had failed. Copaxone, an immunomodulatory amino acid polymer, is approved to treat multiple sclerosis.

However, the Zlokovic report in Nature Neuroscience bolsters the case for Sangamo BioSciences Inc.'s SB-509, a transcriptional activator of VEGF-A, which stimulates blood vessel growth. The study showed that the brains of SOD1 mutant mice have shorter capillaries and lower blood flow than wild-type controls.

Last year, Sangamo reported that SB-509 improved nerve conduction and sensation compared with placebo in a Phase Ib trial in diabetic neuropathy. Spokesperson Liz Wolffe told SciBX that the company plans to begin a Phase II trial of SB-509 for ALS this year.

Meanwhile, Lee told SciBX that her group is forging ahead with a high-throughput screening project through the University of Pennsylvania's Marian S. Ware Alzheimer Program. The group is looking for compounds that modulate TDP-43 localization or activity.

"We want to bridge the gap between target identification, which academia does very well, and the preclinical stuff that generates lead compounds, which is usually done in biotech or pharma," said Lee. "The new model is to bypass the biotech company and do all of the preclinical, toxicity and pharmacodynamics and then negotiate directly" with pharma companies interested in the clinical development of lead compounds.

\section{REFERENCES}

1. Miller, R.G. et al. Cochrane Database Syst. Rev. 1, CD001447; published online Jan. 24, 2007; doi:10.1002/14651858.CD001447.pub2

2. Sreedharan, J. et al. Science; published online Feb. 27, 2008; doi:10.1126/science.1154584

Contact: Christopher E. Shaw, Department of Clinical Neurosciences, King's College London, U.K. e-mail: chris.shaw@iop.kcl.ac.uk

3. Winton, M.J. et al. J. Biol. Chem.; published online Feb. 27, 2008; doi:10.1074/jbc.M800342220

Contact: Virginia M.-Y. Lee, Center for Neurodegenerative Disease Research, University of Pennsylvania School of Medicine, Philadelphia, Pa. e-mail:vmylee@mail.med.upenn.edu

4. Neumann, M. et al. Science 314, 130-133 (2006)

5. Zhong Z. et al. Nat. Neurosci.; published online Mar. 16, 2008; doi:10.1038/nn2073

Contact: Berislav Zlokovic, Center for Neurodegenerative and Vascular Brain Disorders and Departments of Neurosurgery and Neurology, University of Rochester Medical Center, Rochester, N.Y. e-mail: berislav_zlokovic@urmc.rochester.edu

6. Gitcho, M.A. et al. Ann. Neurol.; published online Feb. 20, 2008; doi:10.1002/ana.21344

COMPANIES AND INSTITUTIONS MENTIONED

Isis Pharmaceuticals Inc. (NASDAQ:ISIS), Carlsbad, Calif.

Johns Hopkins University, Baltimore, Md.

King's College London, London, U.K.

Reata Pharmaceuticals Inc., Dallas, Texas

Ruxton Pharmaceuticals Inc., Lutherville, Md.

Sangamo BioSciences Inc. (NASDAQ:SGMO), Richmond, Calif. sanofi-aventis Group (Euronext:SAN; NYSE:SNY), Paris, France Sygnis Pharma AG (FSE:LIO), Heidelberg, Germany Teva Pharmaceutical Industries Ltd. (NASDAQ:TEVA), Jerusalem, Israel University of California, San Francisco, San Francisco, Calif. University of Pennsylvania School of Medicine, Philadelphia, Pa. University of Rochester Medical Center, Rochester, N.Y. 